\title{
Proteomic Characterization of a Mouse Model of Familial Danish Dementia
}

\author{
Monica Vitale, ${ }^{1,2}$ Giovanni Renzone, ${ }^{3}$ Shuji Matsuda, ${ }^{4}$ Andrea Scaloni, ${ }^{3}$ \\ Luciano D'Adamio, ${ }^{4}$ and Nicola Zambrano ${ }^{1,2}$ \\ ${ }^{1}$ Dipartimento di Biochimica e Biotecnologie Mediche, Università degli Studi di Napoli Federico II, 80131 Napoli, Italy \\ ${ }^{2}$ CEINGE Biotecnologie Avanzate, 80145 Napoli, Italy \\ ${ }^{3}$ Proteomics and Mass Spectrometry Laboratory, ISPAAM, National Research Council, 80147 Napoli, Italy \\ ${ }^{4}$ Department of Microbiology and Immunology, Albert Einstein College of Medicine, Bronx, NY 10462, USA
}

Correspondence should be addressed to Nicola Zambrano, zambrano@unina.it

Received 30 December 2011; Accepted 2 February 2012

Academic Editor: Monica Fedele

Copyright ( $(2012$ Monica Vitale et al. This is an open access article distributed under the Creative Commons Attribution License, which permits unrestricted use, distribution, and reproduction in any medium, provided the original work is properly cited.

\begin{abstract}
A dominant mutation in the ITM2B/BRI2 gene causes familial Danish dementia (FDD) in humans. To model FDD in animal systems, a knock-in approach was recently implemented in mice expressing a wild-type and mutant allele, which bears the FDDassociated mutation. Since these $\mathrm{FDD}_{\mathrm{KI}}$ mice show behavioural alterations and impaired synaptic function, we characterized their synaptosomal proteome via two-dimensional differential in-gel electrophoresis. After identification by nanoliquid chromatography coupled to electrospray-linear ion trap tandem mass spectrometry, the differentially expressed proteins were classified according to their gene ontology descriptions and their predicted functional interactions. The Dlg4/Psd95 scaffold protein and additional signalling proteins, including protein phosphatases, were revealed by STRING analysis as potential players in the altered synaptic function of $\mathrm{FDD}_{\mathrm{KI}}$ mice. Immunoblotting analysis finally demonstrated the actual downregulation of the synaptosomal scaffold protein Dlg4/Psd95 and of the dual-specificity phosphatase Dusp3 in the synaptosomes of FDD $\mathrm{KI}_{\mathrm{I}}$ mice.
\end{abstract}

\section{Introduction}

Familial Danish Dementia (FDD) is a neurodegenerative disease characterized by early cataracts, deafness, progressive ataxia, and dementia. Patients with FDD show diffuse brain atrophy and widespread amyloid angiopathy. In FDD, neurofibrillary tangles (NFTs) are the major histological finding in the hippocampus [1-3]. FDD is an autosomal dominant disease caused by the accumulation of the amyloidogenic Cterminal 34 amino acid peptide of BRI2. BRI2, a product of the ITM2B/BRI2 gene, is a type II transmembrane protein of unknown function. Physiologically, BRI2 is cleaved at the Cterminus by furin endoprotease, producing a 23 -amino acid soluble C-terminal fragment [2]. FDD is caused by a decamer duplication in the $3^{\prime}$ region of the ITM2B/BRI2 gene. This mutation produces a longer 34 amino acid C-terminal fragment that accumulates as amyloid $[4,5]$.

FDD and Alzheimer's disease (AD) share neuropathological features, including amyloid deposition and neurodegeneration in the central nervous system [6-8]. The mature form of BRI2 is able to reduce accumulation of the $\mathrm{A} \beta$ peptide [912] while APP catabolites, including $A \beta$, were significantly increased in the brain of FDD patients [13]. The interaction between these two amyloidogenic proteins (BRI2 and APP) can be relevant for the design of new therapeutic strategies for FDD and AD.

To model FDD pathogenesis in animals, several mouse lines have been generated and analyzed so far [14], which include transgenic mice expressing wild-type [15] or mutant $[16,17]$ BRI2 proteins, as well as ITM2B/BRI2 gene knockout mice [10] or ITM2B/BRI2 knock-in mutant mice [18]. The transgenic mice overexpressing the FDD-associated mutation of human ITM2B/BRI2 partially recapitulated the main histopathological features of FDD; they indeed developed cerebral amyloid angiopathy, parenchymal amyloid deposition, and neuroinflammation [14, 16]. Age-dependent deposition of Danish amyloid peptide was also observed in the brain of a second transgenic model, with associated angiopathy and microhemorrhage, neuritic dystrophy, and neuroinflammation [17]. In this model, deposition of 
the Danish peptide also accelerated Tau pathology in a double transgenic model with mutant ITM2B/BRI2 and Tau (P301S) constructs.

To study the pathogenesis of FDD in the absence of potential artifacts due to transgenic overexpression of the mutant protein, a refined mouse model has been recently generated, which is based on a knock-in approach where the exon 6 of the murine ITM2B/BRI2 gene was substituted for by a mutant sequence carrying the human FDD mutation [18]. The analysis of $F D D_{\mathrm{KI}}$ mouse model, carrying a mutant and a wild-type ITM2B/BRI2 allele, has shown that the Danish mutation causes impaired synaptic plasticity and deficits in hippocampal memory, in the absence of cerebral deposits and lesions [19]. A similar scenario applies to a Familial British Dementia (FBD) knock-in model, in which the dominant, mutant ITM2B/BRI2 allele responsible for FBD is associated to memory deficits and loss of BRI2 function, without the histopathological alterations typical to neurodegenerative disorders [20]. In agreement with the previously reported function of BRI2 in the stabilization of APP holoprotein $[9,12], \mathrm{FDD}_{\mathrm{KI}}$ mice also show decreased BRI2 protein levels and increased levels of APP catabolites [19]; the latter evidence recapitulated the occurrence of increased APP metabolites in the brain of an FDD patient [13]. The functional link between ITM2B/BRI2 and APP genes is also strongly supported by the genetic suppression of memory and synaptic dysfunctions in FDD $\mathrm{KI}_{\mathrm{KI}}$ mice by $A P P$ haplodeficiency [19] or inhibition of APP cleavage by $\beta$-secretase [20]. The functional association between ITM2B/BRI2 and APP genes strongly supports the participation of the encoded proteins to synaptic dysfunction. Accordingly, decreased levels of BRI2/APP complexes have been observed in the synaptic membranes of $\mathrm{FDD}_{\mathrm{KI}}$ mice [19].

In this paper, we profiled the expression pattern of synaptosomal proteins in the $\mathrm{FDD}_{\mathrm{KI}}$ mouse model, via differential expression analysis based on two-dimensional differential in-gel electrophoresis (2D-DIGE) in combination with tandem mass spectrometry. Our validated results showed decreased representation of the synaptosomal scaffold protein Psd95/Dlg4 and of the Dusp3 phosphatase in the FDD $\mathrm{KI}_{\text {sy- }}$ naptosomes.

\section{Materials and Methods}

2.1. Mice, Preparation of Synaptosomal Extracts, and 2DDIGE Analysis. Mice were handled according to the Ethical Guidelines for Treatment of Laboratory Animals of the Albert Einstein College of Medicine. The procedures were described and approved in animal protocol number 200404. $\mathrm{FDD}_{\mathrm{KI}}$ mice were on a C57BL/6J background. Crude synaptosomal fractions containing both membrane and soluble synaptosomal proteins were obtained from three biological replicates each of wild-type (C57BL/6J) or FDD $\mathrm{KI}_{\mathrm{KI}}$ mice, as described in [13]. Briefly, mouse brain homogenates in Hepessucrose buffer (20 mM Hepes/NaOH pH 7.4, 1 mM EDTA, $1 \mathrm{mM}$ EGTA, and $0.25 \mathrm{M}$ sucrose) supplemented with protease and phosphatase inhibitors (wt $/ \mathrm{vol}=10 \mathrm{mg}$ tissue/ $100 \mathrm{~mL}$ buffer) were centrifuged at $800 \times \mathrm{g}$ for $10 \mathrm{~min}$, at $4^{\circ} \mathrm{C}$. The supernatant (S1, total brain extract) was separated into supernatant (S2) and pellet (P2) by centrifugation at $9,200 \times \mathrm{g}$ for $15 \mathrm{~min}$, at $4^{\circ} \mathrm{C}$. P2 fractions, representing the crude synaptosomal fractions, were resuspended in $7 \mathrm{M}$ urea, $2 \mathrm{M}$ thiourea, $4 \%$ CHAPS to extract the whole synaptosomal content, then precipitated in acetone/methanol $(8: 1, \mathrm{v}: \mathrm{v})$ for $16 \mathrm{~h}$, at $-20^{\circ} \mathrm{C}$, and finally recovered by centrifugation at $16,000 \times \mathrm{g}$ for $30 \mathrm{~min}$, at $4^{\circ} \mathrm{C}$. The synaptosomal proteins were resuspended in $7 \mathrm{M}$ urea, $2 \mathrm{M}$ thiourea, $4 \%$ CHAPS, and $30 \mathrm{mM}$ Tris- $\mathrm{HCl}$; protein concentration was determined by using the Bradford method (Bio-Rad). Before labelling, the $\mathrm{pH}$ of the samples was adjusted to $\mathrm{pH} 8.5$ with $\mathrm{HCl}$ solutions; each labelling reaction was performed in a $10 \mu \mathrm{L}$ volume with $50 \mu \mathrm{g}$ of the synaptosomal proteins, in the presence of 400 pmol of Cy2-, Cy3-, or Cy5-dyes (minimal labelling dyes, GE Healthcare). A dye-swapping strategy was used to label samples; accordingly, two samples from wild-type synaptosomal extracts were labelled with $\mathrm{Cy} 3$, while the third was labelled with Cy5; in a complementary manner, two samples from $\mathrm{FDD}_{\mathrm{KI}}$ extracts were labelled with $\mathrm{Cy} 5$, and the third was labelled with Cy3. Three mixtures of the 6 samples $(50 \mu \mathrm{g}$ each) were also labelled with Cy 2 dye, as the internal standard required for the 2D-DIGE procedure. The labelling was performed for $30 \mathrm{~min}$, at $0^{\circ} \mathrm{C}$, in the dark, and was chased by the addition of $1 \mathrm{mM}$ lysine. Three sample mixtures, made of appropriate Cy3- and Cy5-labeled pairs and a Cy2-labeled control, were supplemented with $1 \%(\mathrm{v} / \mathrm{v})$ IPG buffer, pH 3-10 NL (GE Healthcare), 1.4\% (v/v) DeStreak reagent (GE Healthcare), and $0.2 \%(\mathrm{w} / \mathrm{v})$ DTT to a final volume of $450 \mu \mathrm{L}$ in $7 \mathrm{M}$ urea, $2 \mathrm{M}$ thiourea, and $4 \%$ CHAPS. The mixtures $(150 \mu \mathrm{g}$ of total protein content) were used to passively hydrate the immobilized $\mathrm{pH}$ gradient IPG gel strips $(24 \mathrm{~cm}, \mathrm{pH} 3-10 \mathrm{NL})$ for $16 \mathrm{~h}$, at $20^{\circ} \mathrm{C}$. Isoelectric focusing (IEF) was carried out with an IPGphor II apparatus (GE Healthcare) up to $75,000 \mathrm{~V} / \mathrm{h}$, at $20^{\circ} \mathrm{C}$ (current limit set to $50 \mu \mathrm{A}$ per strip). The strips were equilibrated in $6 \mathrm{M}$ urea,

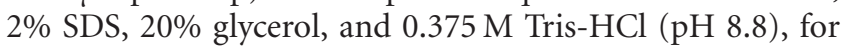
$15 \mathrm{~min}$, in the dark, in the presence of $0.5 \%$ (w:v) DTT, and then in the presence of $4.5 \%(\mathrm{w} / \mathrm{v})$ iodoacetamide in the same buffer, for additional 15 min. Equilibrated IPG stripss were transferred onto $12 \%$ polyacrylamide gels, within low-fluorescence glass plates (ETTAN-DALT 6 system, GE Healthcare). The second-dimension SDS-PAGE was performed by using a DALT II electrophoresis unit (GE Healthcare) at $2 \mathrm{~W} /$ gel for $12 \mathrm{~h}$. Gels were scanned with a Typhoon 9400 variable mode imager (GE Healthcare), using appropriate excitation/emission wavelengths for Cy2 $(488 / 520 \mathrm{~nm})$, Cy3 $(532 / 580 \mathrm{~nm})$, and Cy5 $(633 / 670 \mathrm{~nm})$. Images were acquired in the Image-Quant software (GE Healthcare) and analyzed by using the DeCyder 6.0 software (GE Healthcare). A DeCyder differential in-gel-analysis (DIA) module was used for spot detection and pairwise comparison of each sample (Cy3 and Cy5) to the Cy2, mixed standard present in each gel. The DeCyder biological variation analysis (BVA) module was then used to simultaneously match all of the protein-spot maps from the gels, and to calculate average abundance ratios and $P$ values across the triplicate sets of samples (Student's $t$ test). 
For preparative protein separations, $500 \mu \mathrm{g}$ of unlabeled protein samples from pooled, wild-type, and $\mathrm{FDD}_{\mathrm{KI}}$ synaptosomal samples were used for passive hydration of $24 \mathrm{~cm}$ strips for the first gel dimension (pH 3-10 NL IPG strips, GE Healthcare). The first and second dimension runs were carried out as described above. After 2-DE, gels were fixed and stained with SyproRuby fluorescent stain (Invitrogen). After spot matching with the master gel from the analytical step in the BVA module of DeCyder software, a pick list was generated for spot picking by a robotic picker (Ettan spot picker, GE Healthcare).

2.2. Protein Identification and Bioinformatic Analysis. Spots from 2-DE were excised from gels, minced and washed with water. Proteins were in-gel reduced, S-alkylated, and digested with trypsin, as previously reported [21]. Protein digests were subjected to a desalting/concentration step on $\mu$ ZipTipC18 pipette tips (Millipore Corp., Bedford, MA, USA) and then analyzed by nanoLC-ESI-LIT-MS/MS using a LTQ XL mass spectrometer (ThermoFinnigan, USA) equipped with Proxeon nanospray source connected to an EasynanoLC (Proxeon, Denmark) [21, 22]. Peptide mixtures were separated on an Easy $\mathrm{C}_{18}$ column $(10 \times 0.075 \mathrm{~mm}, 3 \mu \mathrm{m})$ (Proxeon) using a gradient of acetonitrile containing $0.1 \%$ formic acid in aqueous $0.1 \%$ formic acid; acetonitrile ramped from $5 \%$ to $35 \%$ over 15 min and from $35 \%$ to $95 \%$ over $2 \mathrm{~min}$, at a flow rate of $300 \mathrm{~nL} / \mathrm{min}$. Spectra were acquired in the range $\mathrm{m} / \mathrm{z} 400-2000$. Acquisition was controlled by a data-dependent product ion-scanning procedure over the three most abundant ions, enabling dynamic exclusion (repeat count 2 and exclusion duration $1 \mathrm{~min}$ ). The mass isolation window and collision energy were set to $\mathrm{m} / z 3$ and $35 \%$, respectively. MASCOT software package version 2.2 .06 (Matrix Science, UK) [23] was used to identify spots unambiguously from a nonredundant sequence database (all taxa UniProtKB 2010/01/09). NanoLC-ESI-LIT-MS/MS data were searched by using a mass tolerance value of $2 \mathrm{Da}$ for precursor ion and $0.8 \mathrm{Da}$ for MS/MS fragments, trypsin as proteolytic enzyme, a missed cleavages maximum value of 2 and Cys carbamidomethylation, and Met oxidation as fixed and variable modification, respectively. Candidates with more than 2 assigned peptides with an individual MASCOT score $>25$, both corresponding to $P<0.05$ for a significant identification, were further evaluated by the comparison with their calculated mass and pI values, using the experimental values obtained from 2-DE.

Search for functional interaction between proteins identified by MS analysis was performed using the String v. 8.3 database (http://string83.embl.de/) [24]. Gene ontology classification of the identified proteins was performed through the web-accessible DAVID (v 6.7) annotation system (http:// david.abcc.ncifcrf.gov/home.jsp) [25, 26]. Briefly, the identified proteins were converted into RefSeq-protein identifiers through the DAVID Gene ID conversion tool; the new list was then submitted to functional annotation clustering.

2.3. Antibodies and Western Blotting. Western blot analysis was used to validate differential expression data obtained by proteomic analysis. Triplicate synaptosomal samples from wild-type and $\mathrm{FDD}_{\mathrm{KI}}$ mice were separated on $10 \%$ polyacrylamide gels by SDS-PAGE and then blotted on PVDF membranes (GE Healthcare). Filters were blocked in PBS containing 5\% nonfat dry milk and incubated with 1:250 dilutions of the different primary antibodies, obtained from Santa Cruz Biotechnology, except for $\alpha$-tubulin (DM1A; Sigma) antibody. Appropriate secondary IgG horseradish peroxidase conjugated was used as secondary antibody (Southern Biotechnology); bands were visualised by the ECL kit (GE Healthcare).

\section{Results and Discussion}

3.1. Differentially Expressed Proteins in Synaptosomes of $F D D_{\mathrm{KI}}$ Mice. In order to characterize the synaptosomal proteome of the available mouse model of FDD, we used the differential in-gel electrophoresis approach (2D-DIGE), which was applied to synaptosomal extracts from wild-type and $\mathrm{FDD}_{\mathrm{KI}}$ mice. Indeed, three biological replicates of synaptosomal preparations from wild-type and $\mathrm{FDD}_{\mathrm{KI}}$ mice were generated for protein extraction and fluorescence labelling with Cy-dyes. Analysis of the 2D-DIGE images, according to the DeCyder bioinformatic software, allowed us to detect about 2,000 matched protein spots within the three gels. We performed a quantitative and statistical analysis under parameters defined as relative expression ratio in $\mathrm{FDD}_{\mathrm{KI}}$ versus WT mice of $>1.25$ for protein spots upregulated and of $<-1.25$ for protein spots downregulated, with a $P$ value $<0.05$. We found that twelve spots appeared to be deregulated (circled in Figure 1(a)); in particular, four protein spots were upregulated, whereas eight protein spots were downregulated, in $\mathrm{FDD}_{\mathrm{KI}}$ versus WT mice.

In order to identify the differentially expressed proteins, the spots of interest were matched to the corresponding ones from a preparative gel stained with fluorescent stain SyproRuby (yellow circles in Figure 1(b)), which were then individually excised, digested with trypsin, and finally identified by nanoLC-ESI-LIT-MS/MS analysis, as detailed in Methods. Table 1 summarizes the relative spot expression ratios in $\mathrm{FDD}_{\mathrm{KI}}$ versus WT mice as well as the mass spectrometry data for the corresponding identified proteins.

3.2. Functional Classification of the Identified Proteins. In order to find relevant proteins among the multiple identifications obtained by proteomic analysis, we subjected the list of the 13 proteins from Table 1 to bioinformatic analysis in the String database, which integrates interaction data from several bioinformatic sources and provides information about physical and functional, known and predicted interactions of genes and their products [24] (Figure 2). String analysis showed that Dlg4 protein is directly linked to 4 additional proteins, namely Ppp3ca, Hspa8, Atp6vla, and Gnb1. The evidences responsible for those functional associations are mainly experimental (purple line), and reflect protein-protein interactions [27-29]. Indeed, Dlg4, also known as postsynaptic density protein 95 (Psd95), contributes to the organization of multiprotein complexes at the postsynaptic 


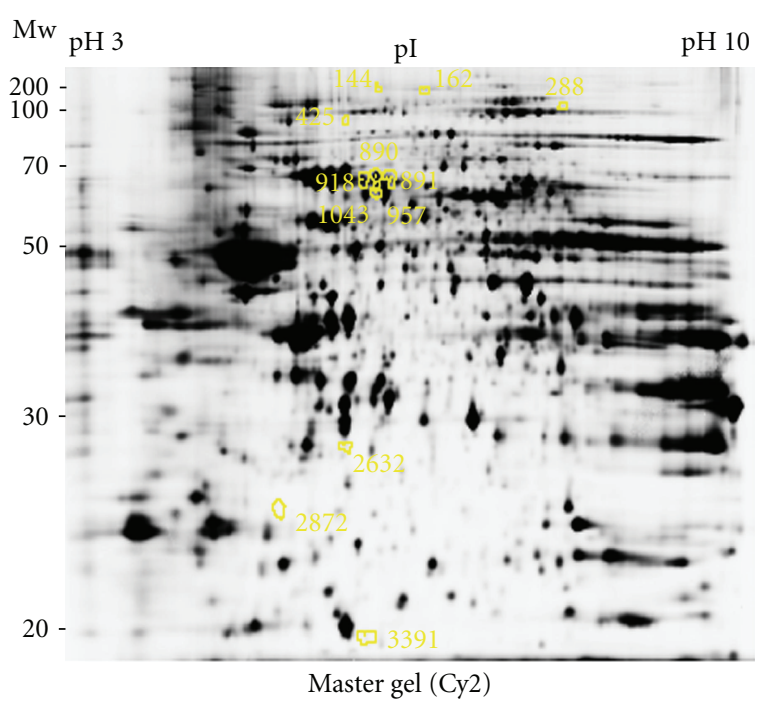

(a)

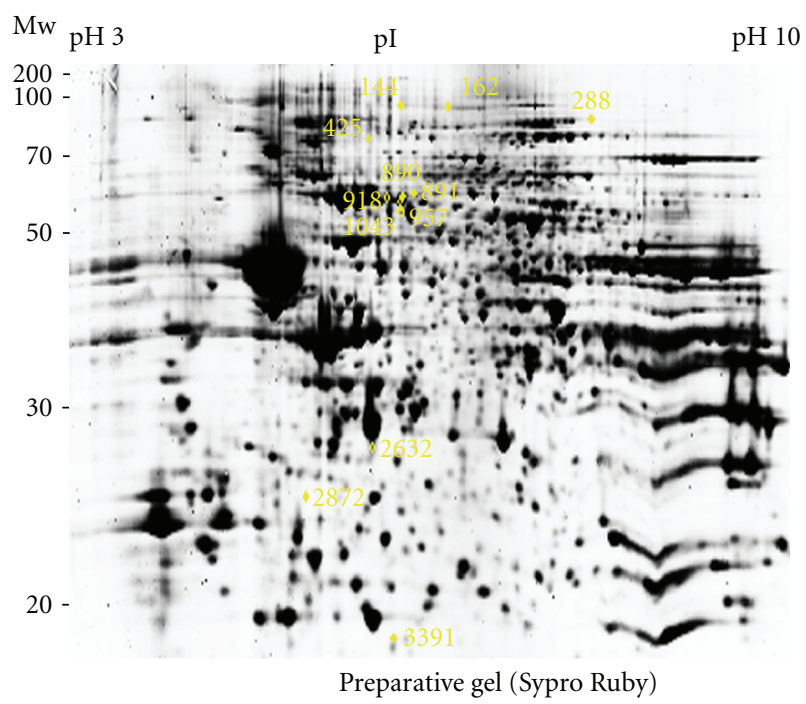

(b)

FIGURE 1: 2-DE map of the differentially expressed protein spots. The figure shows the position on the master (a) and on the preparative (b) gels of the 12 deregulated spots, according to the differential expression analysis of proteins from wild-type and $\mathrm{FDD}_{\mathrm{KI}}$ mouse synaptosomes. In (a), the deregulated spots are surrounded by a yellow border; matched spots within the preparative gel (b) are highlighted by a yellow circle, which also denotes the picking surface for the robotic spot picker. The representative image reported in (a) shows the Cy2-labelled proteins on the scanned master gel; protein spots in (b) were visualized by Sypro Ruby fluorescent staining. Mw: molecular weight; pI: isoelectric point.

contact zone, via its multiple protein interaction domains. This molecular network is made of receptors (i.e., NMDA and AMPA receptors), small signalling proteins (i.e., RasGAP), cell adhesion and cytoskeletal proteins, as well as protein kinases (i.e., CaMKII), thus organizing receptors and signal transduction molecules at the synaptic contact zone $[30,31]$. On its own, Gnb1 is also tightly connected to Gnb2; indeed, the two proteins are the beta 1 and beta 2 components of heterotrimeric $G$ protein complexes, respectively. These proteins share a high protein sequence identity ( $>90 \%$ ) in mouse, in fact they were coidentified in spot 2632 (Table 1). Additional associations involving the differentially expressed proteins in FDD $_{\mathrm{KI}}$ mice involved the kinesin family member 5A (Kif5a), a microtubule-dependent motor protein involved in the axonal transport of neurofilament proteins and organelles, and the kinesin family member 5C (Kif5c), involved in organelle transport. Interestingly, Kif5a and an additional protein identified in this study in multiple deregulated spots (spots $890,891,918$, and 957), namely, dihydropyrimidinase-related protein 2 (Dpysl2), were found as differentially expressed during a proteomic profiling of an AD-transgenic model with preplaque ( 2 months) and plaque (24 months) phenotypes [32].

The DAVID database, which analyzes gene or protein lists deriving from high-throughput experiments and systematically extracts biological meaning from them $[25,26]$, was also used to highlight the functional annotation clustering inside the potential protein network identified by our proteomic analysis. The main descriptor found for molecular functions was the "nucleoside-triphosphatase activity" (GOTERM_MF_ALL; $P=6.2 E-5$ ), which included 6 out of the 13 identified proteins (Atp6vla, Kif5a, Kif5c, Gnb1, Gnb2, and Hspa8; Figure 2, proteins inside the blue box). An additional cluster was associated to the "MAPK signaling pathway" and included heat shock cognate $71 \mathrm{kDa}$ protein (Hspa8) and two phosphatases, namely, protein phosphatase 3, catalytic subunit, alpha isoform (Ppp3ca), and dual specificity phosphatase 3 (Dusp3) (KEGG_Pathway $P=$ $6.2 E-2$ ) (Figure 2, green box). These phosphatases, although at a lower statistical value, were also annotated with the ATPase, $\mathrm{H}^{+}$transporting, lysosomal V1 subunit A (Atp6vla) in the biological process "phosphate metabolic process" (GOTERM_BP_FAT $P=2.7 E-1$ ).

3.3. Validation of 2D-DIGE Results by Western Blot Analysis of Proteins Differentially Expressed in FDD ${ }_{\mathrm{KI}}$ Mice. Differentially expressed proteins from 2D-DIGE analysis were mainly classified according to their functional annotation into "nucleoside-triphosphatase activity" or their involvement in "MAPK signaling pathway" (Figure 2). We then selected some representative members of the two groups, namely Kif5a and Dpysl2, together with Ppp3ca and Dusp3, respectively, to validate our expression results by an alternative method, such as western blotting. An additional downregulated protein, namely Dlg4/Psd95, which is a prominent scaffold protein in synaptosomal architecture/function, and is also associated with nucleoside-triphosphatase activity, was also assayed.

Western blotting analysis definitively demonstrated that Dlg4/Psd95 was slightly downregulated in synaptosomal extracts from $\mathrm{FDD}_{\mathrm{KI}}$ mice, in strong agreement with $2 \mathrm{D}$ DIGE data (expression ratio $-1.27, P=0.025$; see Table 1 ) (Figure 3(a)). In contrast, no positive confirms were observed for the selected proteins associated with "nucleoside-triphosphatase activity," namely, Kif5a and Dpysl2 


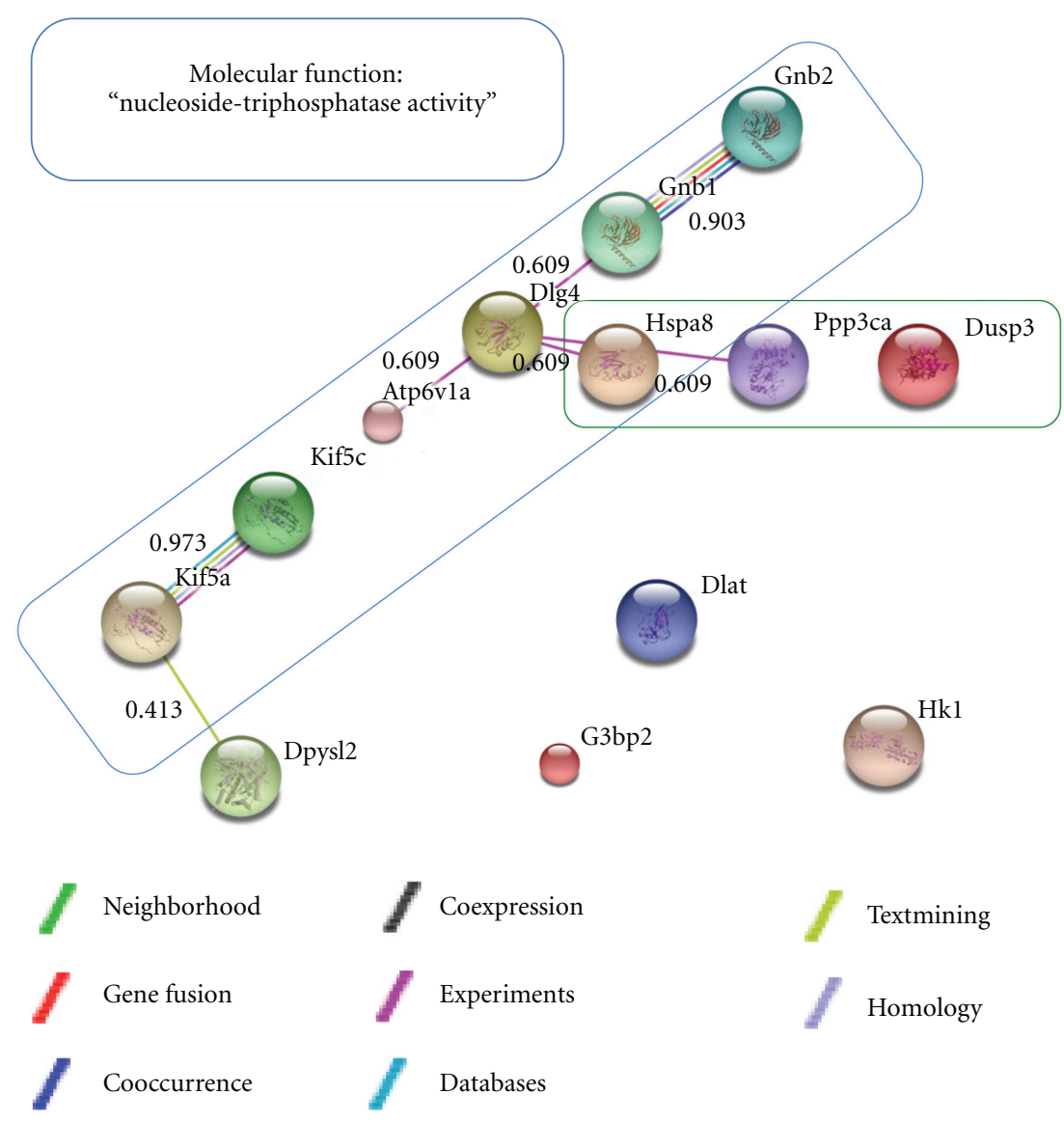

FIGURE 2: Bioinformatic analysis of the differentially expressed proteins. The list of the MS-identified protein spots from 2D-DIGE was subjected to String (v. 8.3) analysis to reveal functional interactions between the deregulated proteins. Interacting proteins are connected by lines of different colors, according to the color code shown at the bottom of the figure. The reported values close to the lines indicate the confidence scores, as revealed by the functional interaction analysis. The original graphic output was modified to fit the proteins in the blue and green boxes, according to their classification under the gene ontology descriptors "Molecular function: nucleoside triphosphatase activity" and "KEGG pathway: MAPK signaling pathway," as revealed by the DAVID (v. 6.7) annotation system.

(Figure 3(a)). Alternative results were obtained for phosphatase members of the "MAPK signaling cascade." In fact, a good correlation between 2D-DIGE and western blotting analysis was observed for Dusp3, while contradictory results were obtained for Ppp3ca (Figure 3(a)). Negative correlation data between the two analytical methods were easily explained on the basis of the differential expression of specific protein isoforms bearing posttranslational modifications. Thus, post-transcriptional events should regulate abundance of specific protein isoforms in $\mathrm{FDD}_{\mathrm{KI}}$ synaptosomes. In this context, protein phosphorylation and dephosphorylation is a relevant process in synaptic activity. For example, after exocytosis for neurotransmitter release, the synaptic vesicles are retrieved by endocytosis to accomplish additional cycles of synaptic transmission. In the paradygm, several proteins involved in synaptic function are dephosphorylated, during synaptic vesicle endocytosis, and rephosphorylated after recycling to guarantee the maintenance of synaptic transmission [33]. Ppp3ca phosphatase is associated to these activities. Although global levels of this protein seemed unchanged in the $\mathrm{FDD}_{\mathrm{KI}}$ synaptosomes by western blotting, 2D-DIGE analysis suggested downregulation of a specific Ppp3ca isoform. On the contrary, Dusp3 downregulation in the $\mathrm{FDD}_{\mathrm{KI}}$ synaptosomes was definitively validated in the synaptosomal preparations, as a nongeneralized phenomenon in mouse brain. In fact, western blot analysis of Dusp3 in crude brain lysates showed slightly increased protein levels in the unfractionated FDD $_{\mathrm{KI}}$ samples (Figure $3(\mathrm{~b})$ ). Dual-specificity phosphatases constitute a heterogeneous group of enzymes with the ability to recognize either phospho-Tyr or phosphoSer/Thr substrates and act in the regulation of JNK- and Erk-mediated pathways [34]. At the present, no evidences have been published that support a Dusp3 function in the nerve system and in synaptic functionality, although one can speculate the involvement of this phosphatase also in the central nerve system, given the relevant functions of the ERK kinases in the signal transduction mechanisms in the brain [35].

\section{Conclusions}

The results of this work outline a differential expression of selected proteins in the synaptosomes of FDD KI $_{\text {mice. Eight }}$ 
TABLE 1: Relative expression and nanoLC-ESI-LIT-MS/MS-based identification of differentially expressed proteins, as revealed by 2D-DIGE analysis of synaptosomal preparations.

\begin{tabular}{|c|c|c|c|c|c|c|c|c|c|}
\hline Spot & Ratio & $P$ value & Accession & Protein & $\begin{array}{l}\text { Short } \\
\text { name }\end{array}$ & $\begin{array}{l}\mathrm{pI} / \mathrm{Mw} \\
\text { theoretical } \\
(\mathrm{kDa})\end{array}$ & Peptides & $\begin{array}{l}\text { Sequence } \\
\text { coverage }\end{array}$ & $\begin{array}{l}\text { Mascot } \\
\text { score }\end{array}$ \\
\hline 144 & -1.85 & 0.029 & P33175 & Kinesin heavy chain isoform $5 \mathrm{~A}$ & Kif5a & $5.67 / 117$ & 2 & 2 & 131 \\
\hline 162 & -1.53 & 0.049 & P28738 & Kinesin heavy chain isoform 5C & Kif5c & $5.84 / 109$ & 6 & 8 & 281 \\
\hline 288 & -1.41 & 0.047 & P17710 & Hexokinase-1 & Hk1 & $6.44 / 108$ & 10 & 12 & 407 \\
\hline 425 & -1.27 & 0.025 & Q62108 & Disks large homolog 4 & $\mathrm{Dlg} 4$ & $5.56 / 80$ & 3 & 4 & 116 \\
\hline \multirow{3}{*}{890} & \multirow{3}{*}{1.51} & \multirow{3}{*}{0.043} & P50516 & $\begin{array}{l}\text { V-type proton ATPase catalytic } \\
\text { subunit A }\end{array}$ & Atp6vla & $5.42 / 68$ & 5 & 11 & 323 \\
\hline & & & P63017 & Heat shock cognate $71 \mathrm{kDa}$ protein & Hspa8 & $5.37 / 71$ & 7 & 12 & 264 \\
\hline & & & O08553 & $\begin{array}{l}\text { Dihydropyrimidinase-related } \\
\text { protein } 2\end{array}$ & Dpysl2 & $5.95 / 62$ & 3 & 6 & 163 \\
\hline \multirow{3}{*}{891} & \multirow{3}{*}{-1.38} & \multirow{3}{*}{0.045} & P50516 & $\begin{array}{l}\text { V-type proton ATPase catalytic } \\
\text { subunit A }\end{array}$ & Atp6vla & $5.42 / 68$ & 8 & 14 & 430 \\
\hline & & & P63017 & Heat shock cognate $71 \mathrm{kDa}$ protein & Hspa8 & $5.37 / 71$ & 5 & 9 & 287 \\
\hline & & & O08553 & $\begin{array}{l}\text { Dihydropyrimidinase-related } \\
\text { protein } 2\end{array}$ & Dpysl2 & $5.95 / 62$ & 3 & 5 & 123 \\
\hline \multirow{3}{*}{918} & \multirow{3}{*}{1.38} & \multirow{3}{*}{0.014} & P50516 & $\begin{array}{l}\text { V-type proton ATPase catalytic } \\
\text { subunit A }\end{array}$ & Atp6vla & $5.42 / 68$ & 9 & 17 & 433 \\
\hline & & & O08553 & $\begin{array}{l}\text { Dihydropyrimidinase-related } \\
\text { protein } 2\end{array}$ & Dpysl2 & $5.95 / 62$ & 5 & 12 & 427 \\
\hline & & & P63017 & Heat shock cognate $71 \mathrm{kDa}$ protein & Hspa8 & $5.37 / 71$ & 8 & 13 & 336 \\
\hline \multirow[t]{2}{*}{957} & \multirow[t]{2}{*}{1.31} & \multirow[t]{2}{*}{0.041} & O08553 & $\begin{array}{l}\text { Dihydropyrimidinase-related } \\
\text { protein } 2\end{array}$ & Dpysl2 & $5.95 / 62$ & 13 & 31 & 925 \\
\hline & & & P97379 & $\begin{array}{l}\text { Ras GTPase-activating } \\
\text { protein-binding protein } 2\end{array}$ & G3bp2 & $5.44 / 54$ & 3 & 6 & 146 \\
\hline 1043 & 1.35 & 0.026 & Q8BMF4 & $\begin{array}{l}\text { Dihydrolipoyllysine-residue } \\
\text { acetyltransferase component of } \\
\text { pyruvate dehydrogenase complex, } \\
\text { mitochondrial }\end{array}$ & Dlat & $5.70 / 59$ & 5 & 9 & 260 \\
\hline \multirow[t]{2}{*}{2632} & \multirow[t]{2}{*}{-1.26} & \multirow[t]{2}{*}{0.018} & P62874 & $\begin{array}{l}\text { Guanine nucleotide-binding } \\
\text { protein } G(\mathrm{I}) / \mathrm{G}(\mathrm{S}) / \mathrm{G}(\mathrm{T}) \text { subunit } \\
\text { beta-1 }\end{array}$ & Gnb1 & $5.60 / 37$ & 6 & 21 & 361 \\
\hline & & & P62880 & $\begin{array}{l}\text { Guanine nucleotide-binding } \\
\text { protein } G(\mathrm{I}) / \mathrm{G}(\mathrm{S}) / \mathrm{G}(\mathrm{T}) \text { subunit } \\
\text { beta-2 }\end{array}$ & Gnb2 & $5.60 / 37$ & 6 & 21 & 327 \\
\hline 2872 & -1.29 & 0.041 & P63328 & $\begin{array}{l}\text { Serine/threonine-protein } \\
\text { phosphatase } 2 \mathrm{~B} \text { catalytic subunit } \\
\text { alpha isoform }\end{array}$ & Ppp3ca & $5.58 / 59$ & 4 & 10 & 180 \\
\hline 3391 & -1.50 & 0.043 & Q9D7X3 & $\begin{array}{l}\text { Dual specificity protein } \\
\text { phosphatase } 3\end{array}$ & Dusp3 & $6.07 / 20$ & 3 & 24 & 217 \\
\hline
\end{tabular}

protein spots were downregulated, while four protein spots

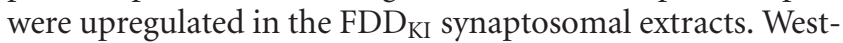
ern blot analysis on selected proteins, guided by the results of bioinformatic classification of the deregulated proteins, showed that two signalling proteins, namely, Dlg4/Psd95 and Dusp3, were actually downregulated in the available animal model of FDD. The first one (Dlg4/Psd95) is a well-known scaffold protein in synaptic function, and its downrepresentation in the synaptosomes of $\mathrm{FDD}_{\mathrm{KI}}$ mice may impair synaptic transmission and activity. The second protein (Dusp3), a know regulator of Jnk- and Erk-mediated pathways, is not as well studied in the central nerve system. However, the evidence provided may stimulate further studies at the phosphoproteomic and functional levels, to assess its synaptosomal targets, and to define the role of its downregulation in brain physiology and in the mechanisms associated with FDD and additional neurodegenerative disorders, including FBD and AD. 


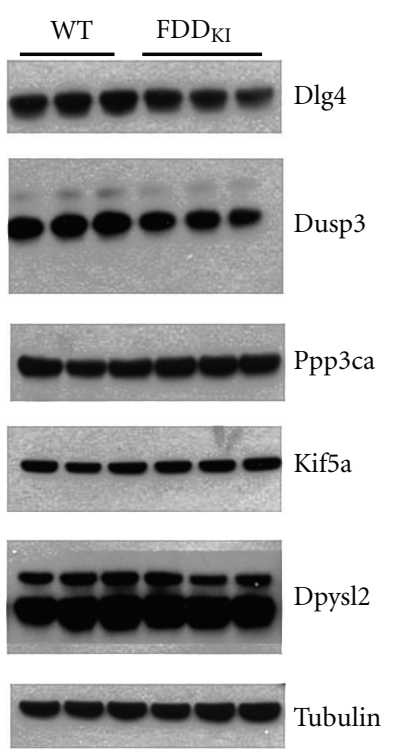

(a)

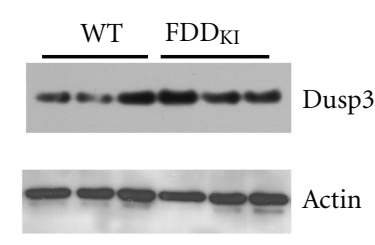

(b)

FIGURE 3: Validation of the 2D-DIGE results by western blot analysis. (a) Triplicate synaptosomal preparations from wild-type and $\mathrm{FDD}_{\mathrm{KI}}$ mouse synaptosomes were separated on SDS-PAGE gels and transferred to membranes for western blot analysis with antibodies against the indicated proteins. Actual downregulation in the synaptosomal samples of FDD ${ }_{\mathrm{KI}}$ mice can be observed for Dlg4/Psd95 and Dusp3 proteins. $\alpha$-Tubulin antibody was used to show equal loading of the protein extracts. (b) Total brain homogenates from wild-type and $\mathrm{FDD}_{\mathrm{KI}}$ mice were analyzed by western blot with antibodies against Dusp3. Actin antibody was used to show equal loading of the protein extracts.

\section{Abbreviations}

2-DE:

2D-DIGE:

$\mathrm{AD}$ :

FBD:

FDD:

MS:

nanoLC-ESI-LIT-MS/MS: Nanoliquid chromatography coupled to electrospray-linear ion trap tandem mass spectrometry

SDS-PAGE: Sodium dodecyl sulphatepolyacrilamide gel electrophoresis.

\section{Acknowledgments}

N. Zambrano has been supported by funds from Ministero dell'Università e della Ricerca Scientifica (PS 126-Ind) and from Regione Campania (L.R. n. 5, Annualità 2007), and L. D'Adamio has been supported by Grants from Alzheimer's

Association (IIRG-09-129984 and ZEN-11-201425), the Edward N. \& Della L. Thome Memorial Foundation grant, and the National Institutes of Health (NIH; R01AG033007). Authors thank T. Russo and the Centro Regionale di Competenza Genomics for Applied Research, Regione Campania (GEAR) for granting access to the 2D-DIGE facility. M. Vitale and G. Renzone gave an equal contribution to this work.

\section{References}

[1] G. T. Plant, T. Revesz, R. O. Barnard, A. E. Harding, and P. C. Gautier-Smith, "Familial cerebral amyloid angiopathy with nonneuritic amyloid plaque formation," Brain, vol. 113, no. 3, pp. 721-747, 1990.

[2] R. Vidal, T. Révész, A. Rostagno et al., "A decamer duplication in the 3 ' region of the BRI gene originates an amyloid peptide that is associated with dementia in a Danish kindred," Proceedings of the National Academy of Sciences of the United States of America, vol. 97, no. 9, pp. 4920-4925, 2000.

[3] J. L. Holton, T. Lashley, J. Ghiso et al., "Familial Danish dementia: a novel form of cerebral amyloidosis associated with deposition of both amyloid-Dan and amyloid-Beta," Journal of Neuropathology and Experimental Neurology, vol. 61, no. 3, pp. 254-267, 2002.

[4] R. Vidal, B. Franglone, A. Rostagno et al., "A stop-codon mutation in the BRI gene associated with familial British dementia," Nature, vol. 399, no. 6738, pp. 776-781, 1999.

[5] J. Ghiso, A. Rostagno, Y. Tomidokoro et al., "Genetic alterations of the BRI2 gene: familial British and Danish dementias," Brain Pathology, vol. 16, no. 1, pp. 71-79, 2006.

[6] J. L. Holton, J. Ghiso, T. Lashley et al., "Regional distribution of amyloid-Bri deposition and its association with neurofibrillary degeneration in familial British dementia," American Journal of Pathology, vol. 158, no. 2, pp. 515-526, 2001.

[7] A. Rostagno, T. Revesz, T. Lashley et al., "Complement activation in chromosome 13 dementias: similarities with Alzheimer's disease," The Journal of Biological Chemistry, vol. 277, no. 51, pp. 49782-49790, 2002.

[8] M. Tsachaki, J. Ghiso, and S. Efthimiopoulos, "BRI2 as a central protein involved in neurodegeneration," Biotechnology Journal, vol. 3, no. 12, pp. 1548-1554, 2008.

[9] S. Matsuda, L. Giliberto, Y. Matsuda et al., "The familial dementia BRI2 gene binds the alzheimer gene amyloid- $\beta$ precursor protein and inhibits amyloid- $\beta$ production," The Journal of Biological Chemistry, vol. 280, no. 32, pp. 28912-28916, 2005.

[10] S. Matsuda, L. Giliberto, Y. Matsuda, E. M. McGowan, and L. D'Adamio, "BRI2 inhibits amyloid $\beta$-peptide precursor protein processing by interfering with the docking of secretases to the substrate," Journal of Neuroscience, vol. 28, no. 35, pp. 8668-8676, 2008.

[11] S. Matsuda, Y. Matsuda, E. L. Snapp, and L. D'Adamio, "Maturation of BRI2 generates a specific inhibitor that reduces APP processing at the plasma membrane and in endocytic vesicles," Neurobiology of Aging, vol. 32, no. 8, pp. 1400-1408, 2011.

[12] A. Fotinopoulou, M. Tsachaki, M. Vlavaki et al., "BRI2 interacts with amyloid precursor protein (APP) and regulates amyloid $\beta(\mathrm{A} \beta)$ production," The Journal of Biological Chemistry, vol. 280, no. 35, pp. 30768-30772, 2005.

[13] S. Matsuda, R. Tamayev, and L. D'Adamio, "Increased A $\beta$ PP processing in familial danish dementia patients," Journal of Alzheimer's Disease, vol. 27, no. 2, pp. 385-391, 2011. 
[14] H. J. Garringer, J. Murrell, L. D'Adamio, B. Ghetti, and R. Vidal, "Modeling familial British and Danish dementia," Brain Structure and Function, vol. 214, no. 2-3, pp. 235-244, 2010.

[15] F. Pickford, J. Coomaraswamy, M. Jucker, and E. McGowan, "Modeling familial British dementia in transgenic mice," Brain Pathology (Zurich, Switzerland), vol. 16, no. 1, pp. 80-85, 2006.

[16] R. Vidal, A. G. Barbeito, L. Miravalle, and B. Ghetti, "Cerebral amyloid angiopathy and parenchymal amyloid deposition in transgenic mice expressing the Danish mutant form of human BRI2," Brain Pathology (Zurich, Switzerland), vol. 19, no. 1, pp. 58-68, 2009.

[17] J. Coomaraswamy, E. Kilger, H. Wölfing et al., "Modeling familial Danish dementia in mice supports the concept of the amyloid hypothesis of Alzheimer's disease," Proceedings of the National Academy of Sciences of the United States of America, vol. 107, no. 17, pp. 7969-7974, 2010.

[18] L. Giliberto, S. Matsuda, R. Vidal, and L. D’Adamio, “Generation and initial characterization of FDD knock in mice," PLoS ONE, vol. 4, no. 11, Article ID e7900, 2009.

[19] R. Tamayev, S. Matsuda, M. Fà, O. Arancio, and L. D'Adamio, "Danish dementia mice suggest that loss of function and not the amyloid cascade causes synaptic plasticity and memory deficits," Proceedings of the National Academy of Sciences of the United States of America, vol. 107, no. 48, pp. 20822-20827, 2010.

[20] R. Tamayev, L. Giliberto, W. Li et al., "Memory deficits due to familial British dementia BRI2 mutation are caused by loss of BRI2 function rather than amyloidosis," Journal of Neuroscience, vol. 30, no. 44, pp. 14915-14924, 2010.

[21] F. Talamo, C. D’Ambrosio, S. Arena et al., "Proteins from bovine tissues and biological fluids: defining a reference electrophoresis map for liver, kidney, muscle, plasma and red blood cells," Proteomics, vol. 3, no. 4, pp. 440-460, 2003.

[22] G. S. Scippa, M. Rocco, M. Ialicicco et al., "The proteome of lentil (Lens culinaris Medik.) seeds: discriminating between landraces," Electrophoresis, vol. 31, no. 3, pp. 497-506, 2010.

[23] W. J. Qian, T. Liu, M. E. Monroe et al., "Probability-based evaluation of peptide and protein identifications from tandem mass spectrometry and SEQUEST analysis: the human proteome," Journal of Proteome Research, vol. 4, no. 1, pp. 53-62, 2005.

[24] D. Szklarczyk, A. Franceschini, M. Kuhn et al., "The STRING database in 2011: functional interaction networks of proteins, globally integrated and scored," Nucleic Acids Research, vol. 39, supplement 1, pp. D561-D568, 2011.

[25] D. W. Huang, B. T. Sherman, and R. A. Lempicki, "Systematic and integrative analysis of large gene lists using DAVID bioinformatics resources," Nature Protocols, vol. 4, no. 1, pp. 44-57, 2009.

[26] D. W. Huang, B. T. Sherman, and R. A. Lempicki, "Bioinformatics enrichment tools: paths toward the comprehensive functional analysis of large gene lists," Nucleic Acids Research, vol. 37, no. 1, pp. 1-13, 2009.

[27] H. Husi, M. A. Ward, J. S. Choudhary, W. P. Blackstock, and S. G. N. Grant, "Proteomic analysis of NMDA receptor-adhesion protein signaling complexes," Nature Neuroscience, vol. 3, no. 7, pp. 661-669, 2000.

[28] M. O. Collins, H. Husi, L. Yu et al., "Molecular characterization and comparison of the components and multiprotein complexes in the postsynaptic proteome," Journal of Neurochemistry, vol. 97, supplement 1, pp. 16-23, 2006.

[29] E. Fernández, M. O. Collins, R. T. Uren et al., “Targeted tandem affinity purification of PSD-95 recovers core postsynaptic complexes and schizophrenia susceptibility proteins," Molecular Systems Biology, vol. 5, article 269, 2009.

[30] E. Kim and M. Sheng, "PDZ domain proteins of synapses," Nature Reviews Neuroscience, vol. 5, no. 10, pp. 771-781, 2004.

[31] A. Alexa, J. Varga, and A. Reményi, "Scaffolds are "active" regulators of signaling modules," FEBS Journal, vol. 277, no. 21, pp. 4376-4382, 2010.

[32] N. Guerreiro, M. Staufenbiel, and B. Gomez-Mancilla, "Proteomic 2-D DIGE profiling of APP23 transgenic mice brain from pre-plaque and plaque phenotypes," Journal of Alzheimer's Disease, vol. 13, no. 1, pp. 17-30, 2008.

[33] V. Anggono, K. J. Smillie, M. E. Graham, V. A. Valova, M. A. Cousin, and P. J. Robinson, "Syndapin I is the phosphorylation-regulated dynamin I partner in synaptic vesicle endocytosis," Nature Neuroscience, vol. 9, no. 6, pp. 752-760, 2006.

[34] K. I. Patterson, T. Brummer, P. M. O’Brien, and R. J. Daly, "Dual-specificity phosphatases: critical regulators with diverse cellular targets," Biochemical Journal, vol. 418, no. 3, pp. 475489, 2009.

[35] J. D. Sweatt, "Mitogen-activated protein kinases in synaptic plasticity and memory," Current Opinion in Neurobiology, vol. 14, no. 3, pp. 311-317, 2004. 


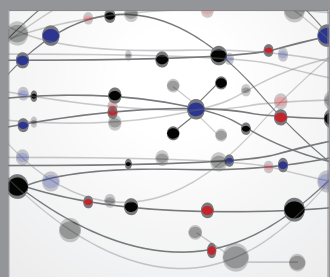

The Scientific World Journal
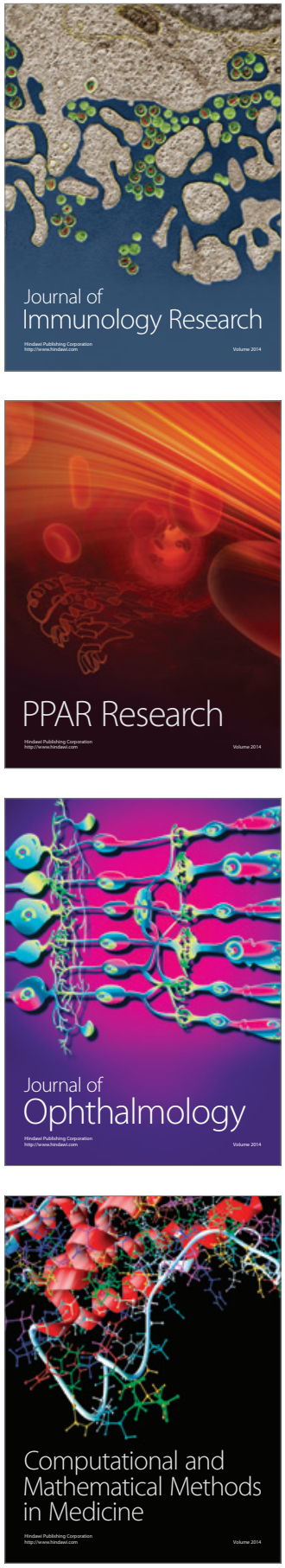

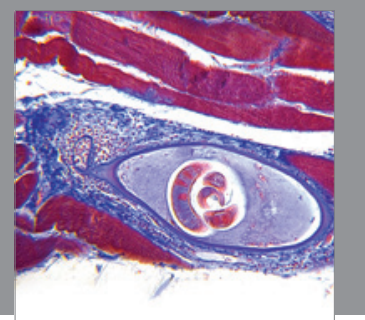

Gastroenterology

Research and Practice
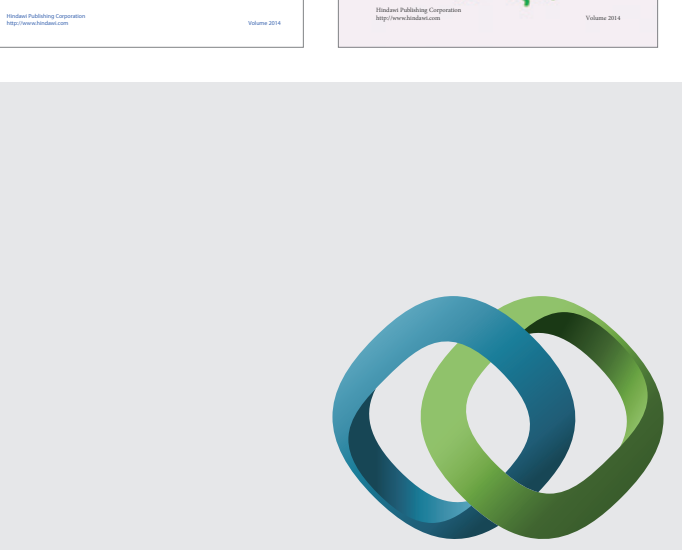

\section{Hindawi}

Submit your manuscripts at

http://www.hindawi.com
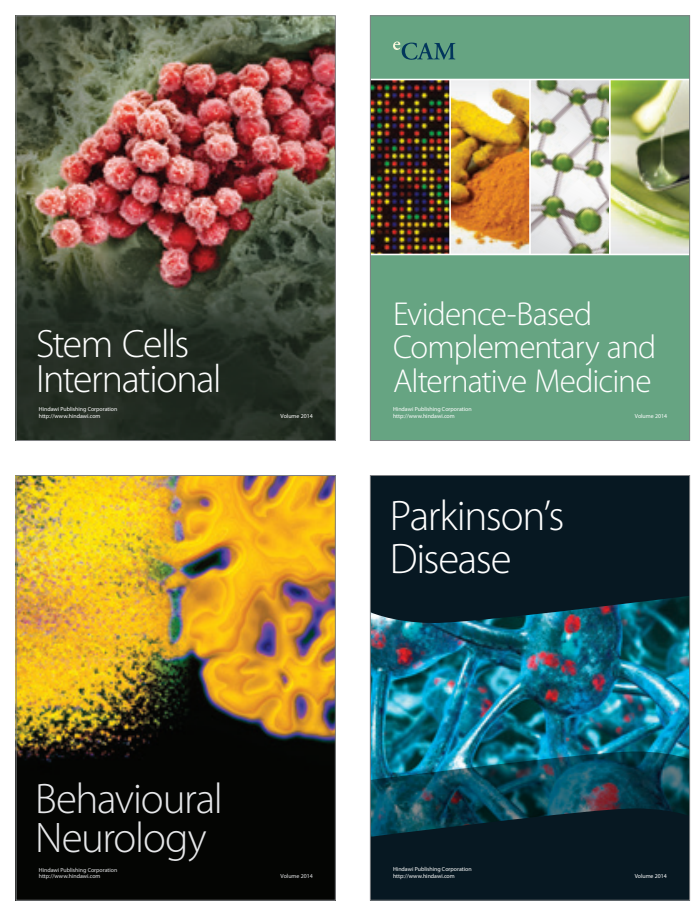

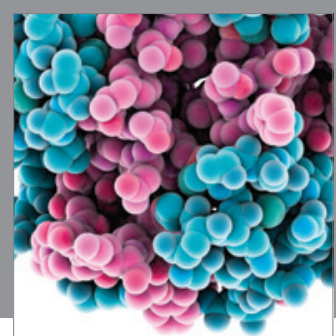

Journal of
Diabetes Research

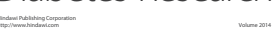

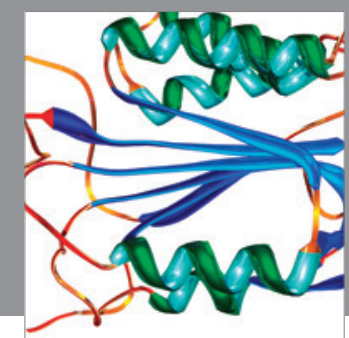

Disease Markers
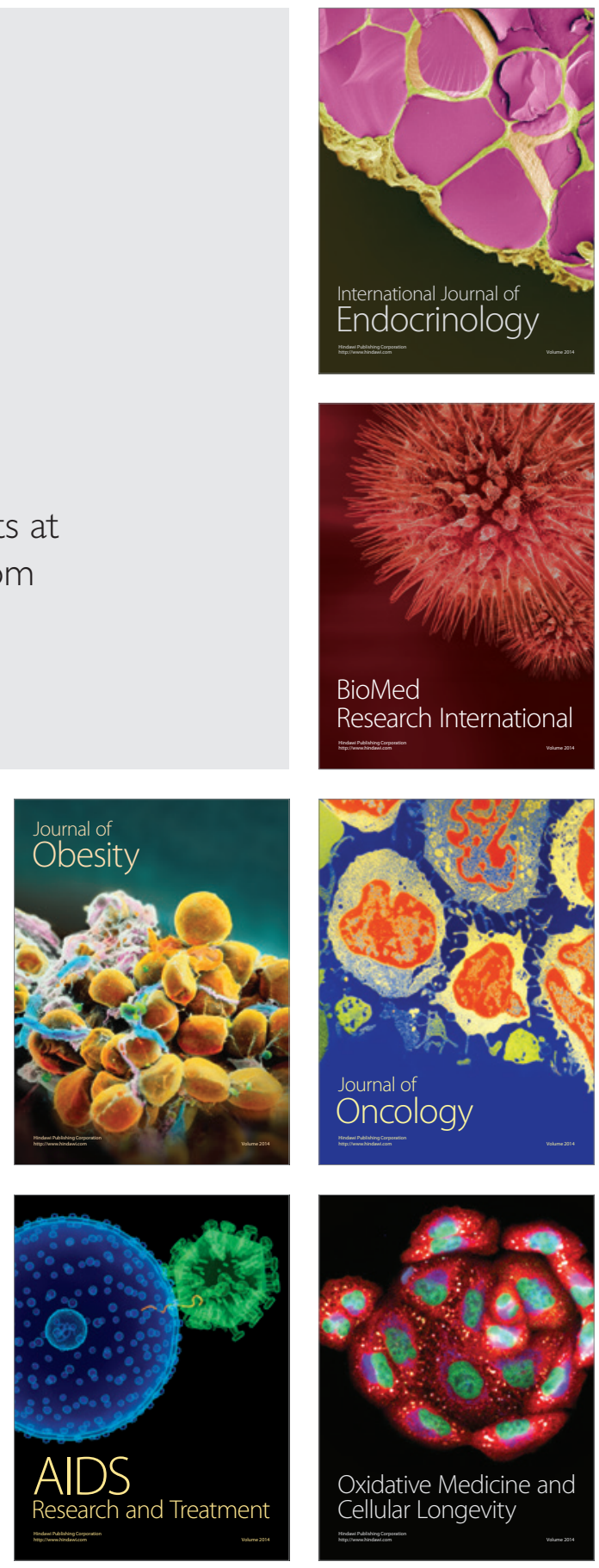